\title{
CONTRIBUIÇÃO AO CONHECIMENTO GEOLÓGICO DA REGIÃO METROPOLITANA DE PORTO ALEGRE, MUNICÍPIOS DE NOVO HAMBURGO, SÃO LEOPOLDO E CAMPO BOM
}

Luis Eduardo de Souza Robaina, Edgardo Ramos Medeiros e Carlos Alberto da Fonseca Pires

LAGEOLAM/Departamento de Geociências - Centro de Ciências Naturais e Exatas UFSM - Santa Maria, RS

\section{RESUMO}

Este trabalho apresenta o mapeamento geológico na região de São Leopoldo, Novo Hamburgo e Campo Bom. Através do mapeamento foi possível reconhecer sedimentos do Permiano e Triássico além de rochas vulcânicas da Bacia do Paraná.

As seqüências sedimentares são ordenadas pelas características litológicas, texturais e estruturais, além dos aspectos geomorfológicos determinando as unidades estratigráficas. A identificação mineralógica foi realizada através da difratometria de raios-X. O quartzo, feldspato, ilita e kaolinita são os principais minerais.

As condições deposicionais, como também as relações de contato entre as seqüências estão apresentadas no trabalho. Na altitude ao redor de $100 \mathrm{~m}$ ocorre a transição entre a parte sedimentar e a parte vulcânica.

As seqüências recentes estão representadas por sedimentos arenosos e argilosos. 


\section{ABSTRACT}

This paper deals with geological mapping of the metropolitan region of São Leopoldo, Novo Hamburgo and Campo Bom cities. Through the geological mapping it was possible to recognize Permian and Triassic sediments and vulcanic rocks from the Parana Basin.

The litological, textural and structural characteristics of sedimentary sequences were focused in order to such as the geomorphological aspects the separation and piling up the stratigraphic units. It was possible to identify the minerology of the most fine sediments with the use os diphatometry X. rays Quartz and feldspar were identif with ilite in the fine sediments and kaolinite in the sandy part.

The depositional conditions as well as relations contact between the sequences were also discussed. The transitions leve of the sedimentary part to the vulcanic part, happens at about $100 \mathrm{~m}$ of altitude.

The recents sedimentary sequences are unconsolidate clay and sandy sediments.

\section{INTRODUÇÃO}

Esse trabalho está incluído nos estudos sobre o meio físico da região de influência do Rio dos Sinos, no trecho compreendido entre o Arroio Sapiranga e a Ilha Quilombo, definida pelas coordenadas geográficas $51^{\circ} 00^{\prime} 00^{\prime \prime}$ e $51^{\circ} 10^{\prime} 17^{\prime \prime}$ de longitude e $29^{\circ} 36^{\prime} 54^{\prime \prime}$ e $29^{\circ} 47^{\prime} 42^{\prime \prime}$ de latitude (Fig.1). 


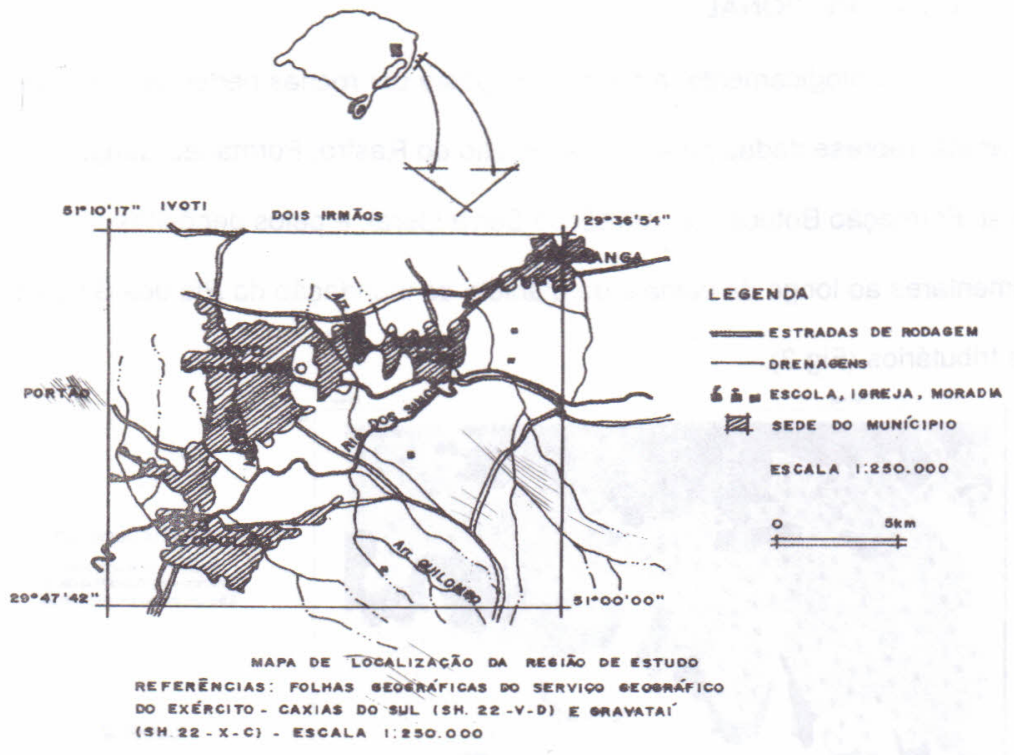

FIGURA 1 : Mapa de localização

\section{METODOLOGIA}

No desenvolvimento do trabalho de levantamento geológico, utilizouse como base de dados, as cartas do Serviço do Exército em escala 1:50.000 SH22-I-IV-2, Novo Hamburgo, e SH-22-I-IV-4, São Leopoldo; o mapeamento da folha de São Leopoldo (Zelter et al, 1992); o mapeamento da folha de Novo Hamburgo (Andreis et al, 1984); os estudos apresentados por Faccini (1989) na sua dissertação de mestrado; e fotografias aéreas.

O trabalho apıesenta uma nova interpretação para o mapeamento geológico na região, identifica as diferentes litologias e caracteriza a textura das rochas sedimentares e a mineralogia através da técnica de difração de raios-X. 


\section{GEOLOGIA REGIONAL}

Geologicamente, a área é composta por rochas pertencentes a Bacia do Paraná, representadas pela Formação Rio do Rastro, Formação Sanga do Cabral, Formação Botucatu e Formação Serra Geral, e pelos depósitos sedimentares ao longo da calha e da planície de inundação do Rio dos Sinos e seus tributários (Fig.2).

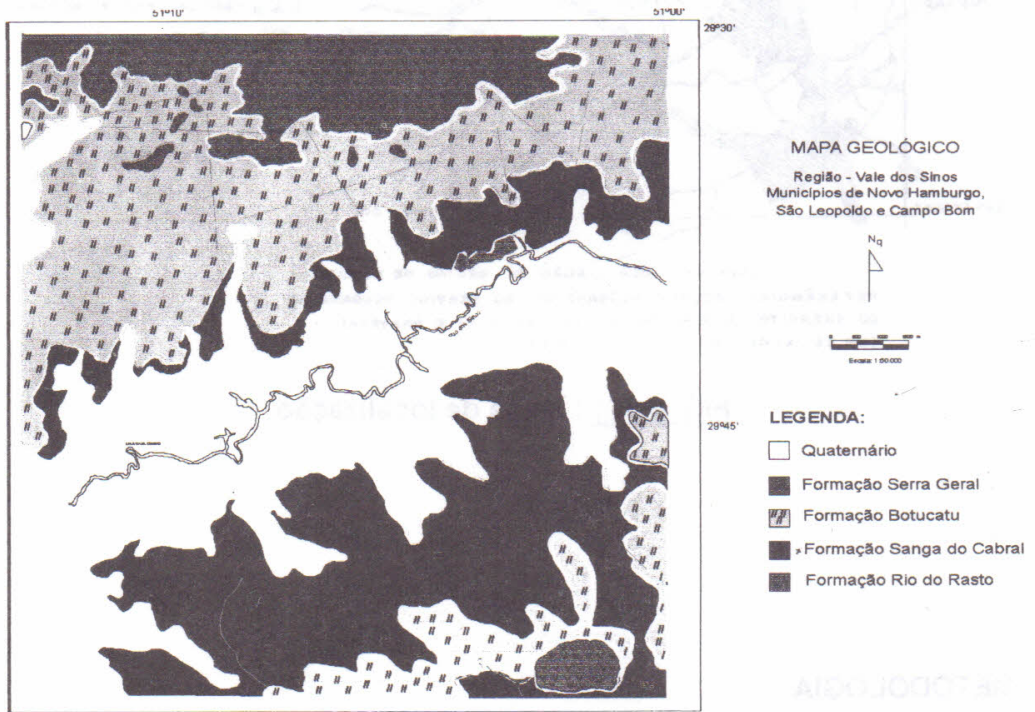

\section{FIGURA 2 : Mapa geológico}

A Bacia do Paraná estabeleceu-se entre o final do Ordoviciano e o início do Siluriano sobre a crosta continental do supercontinente Gondwana. A subsidência termal devido ao resfriamento de extensas áreas aquecidas pelos eventos tecto-magmáticos da orogênese Brasiliana/Pan-Africana, constitui uma hipótese de mecanismo inicial de formação da bacia (Gabaglia \& Milani,1990).

A estratigrafia da Bacia do Paraná consiste, basicamente de cinco seqüências deposicionais principais, que variam em idade do Ordoviciano ao 
Cretáceo. As três seqüências paleozóicas representam ciclos quase completos de transgressão-regressão marinha. $\mathrm{Na}$ região de estudo, está representado pela Formação Rio do Rastro, uma seqüência regressiva do final do Paleozóico.

No Mesozóico, o mar não mais retornou a Bacia do Paraná. As seqüências Mesozóicas são estritamente continentais e estão muito bem representadas na área de estudo. A seqüência Triássica (Grupo Rosário do Sul e Formação Pirambóia) consiste de uma variedade alternativa de ambientes lacustres, fluviais e eólicos, enquanto a seqüência Juro-Cretácea representa um grande deserto de dunas arenosas (Formação Botucatu). Esse imenso desrto é coberto por um expressivo derrame vulcânico (Formação Serra Geral).

\section{CONSIDERAÇÕES GEOLÓGICAS DA ÁREA DE ESTUDO}

As litologias mais antigas, na área em estudo, correspondem, segundo Andreis et al (1984) ao Grupo Passa Dois, Formação Rio do Rastro. Ocorrem afloramentos no Município de Campo Bom, representada pelo ponto de Latitude 29 '41'26" S e Longitude 5103'16” W (Fig.3).

A seqüência está representada por camadas pelíticas e camadas arenosas, que lembram lobos de suspensão. As estruturas sedimentares passiveis de observação, foram estratos cruzados tabulares, laminação plano paralelo, climbing ripples e estratificação do tipo wavy e flaser (Fig.4).

As fácies finas, na área de estudo, são dominantemente constituídas pela fração silte-argila (68\%) e secundariamente pela fração areia fina a muito fina. As fácies arenosas apresentam uma porção basal de arenito médio a grosso e uma porção médio-superior constituida de tamanho areia fina, com importante contribuição do tamanho silte e argila (Tabela 1, em anexo). 


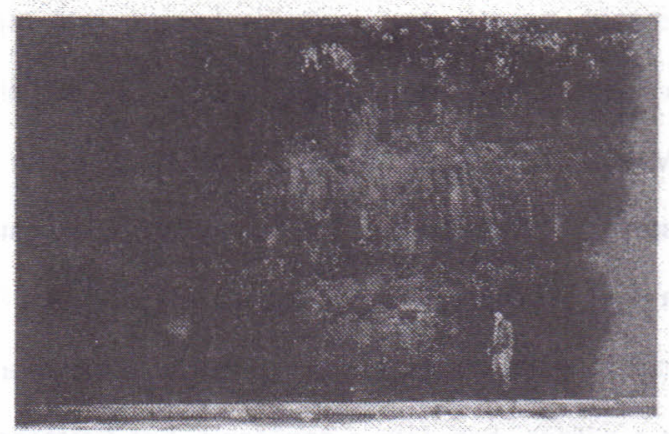

FIGURA 3 : Vista geral da exposição litológica da Formação Rio do Rastro, município de Campo Bom.

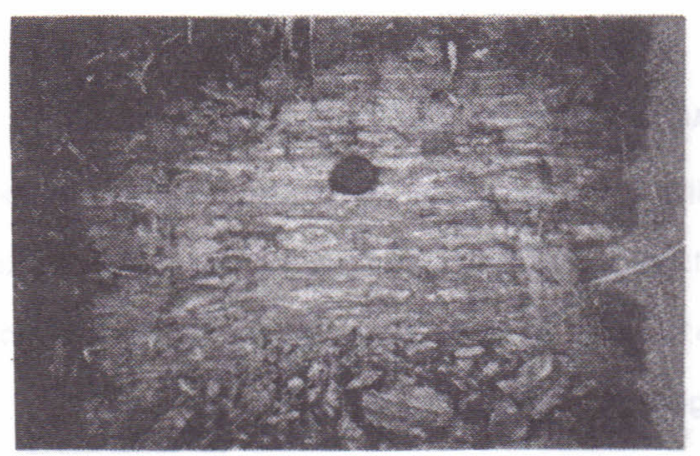

FIGURA 4 : Detalhes da fração fina, com estratificação tipo wavy da Formação Rio do Rasto.

As análises por difração de raios-X (Figs. 5 e 6), das amostras coletadas em superfície, nermitiram identificar, além de quartzo e de poucos feldspatos, argilo-minerais ilita e caolinita; com predomínio da ilita, na fração fina e da caolinita na fração arenosa. 


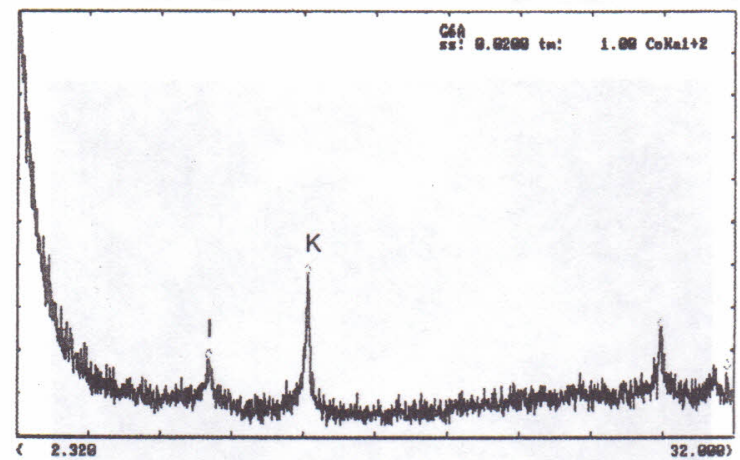

FIGURA 5 : Difração de raio-X, fração arenosa, Formação Rio do Rasto.

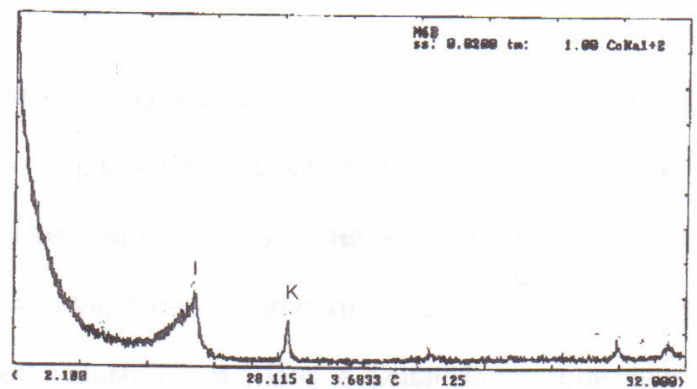

FIGURA 6 : Difração de raio-X, Formação Rio do Rasto.

Sobreposto às litologias da Formação Rio do Rastro em contato transicional (Faccini, 1989), ocorrem as litologias pertencentes ao Grupo Rosário do Sul, Formação Sanga do Cabral. No conjunto, a seqüência é essencialmente constituída de arenitos e em proporções variadas de pelitos e ruditos. As cores vermelho e castanho-avermelhada são típicas.

Os arenitos, litótipo dominante da seqüência (Fig.7), variam de tamanho de grão muito grosso até fino, com predomínio do intervalo granulométrico de muito fino a fino, com importante contribuição da fração silteargila (Tabela 1, em anexo). 


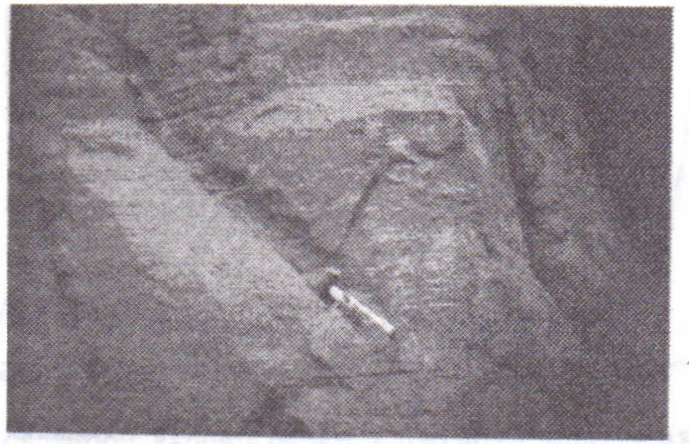

FIGURA 7 : Fácie arenítica da Formação Sanga do Cabral, município de Campo Bom.

Segundo Andreis et al. (1982), a composição eqüivale às categorias de subarcósios ou arcósios pois contém até $30 \%$ de feldspatos. A presença da matriz argilosa e de micas é uma característica importante identificada na área de estudo. de micas é uma característica importante identificada na área de estudo. Nas amostras analisadas, caolinita(K) e ilita(I) mal cristalizadas são os argilominerais encontrados (Fig. 8).

As porções rudíticas subordinadas ocorrem sempre em acumulações lenticulares e corresponde a brechas e a conglomerados intraformacionais, cujo arcabouço é constituido por clastos de rochas pelíticas (FIG.9). Ocorrem, ainda, delgadas intercalações de conglomerados polimíticos formado por seixos de quartzo, rochas ígneas e metamórficas, com matriz de areia grossa (Tabela 1, em anexo).

As rochas correspondentes às porções pelíticas são normalmente constituidas por siltito, com raras ocorrências de argilitos. Ocorrem camadas arenosas silicificadas de espessura centimétrica a métrica, na forma de corpos tabulares (Fig.10). A associação destas litofácies tem sido interpretada como de 
origem fluvial em rios meandrantes, onde as areias correspondem às barras de pontal sobrepostas às fácies conglomeráticas de resíduo de canal e os pelitos, às fácies de planície de inundação (Faccini, 1989).

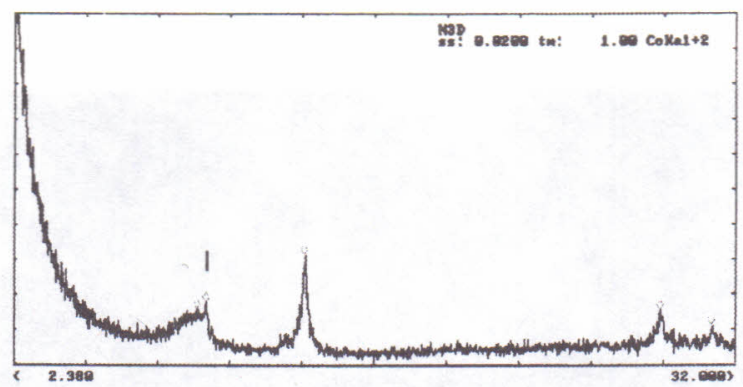

FIGURA 8 : Difração de raio-x, fração silte-argila dos arenitos da Formação Sanga do Cabral.

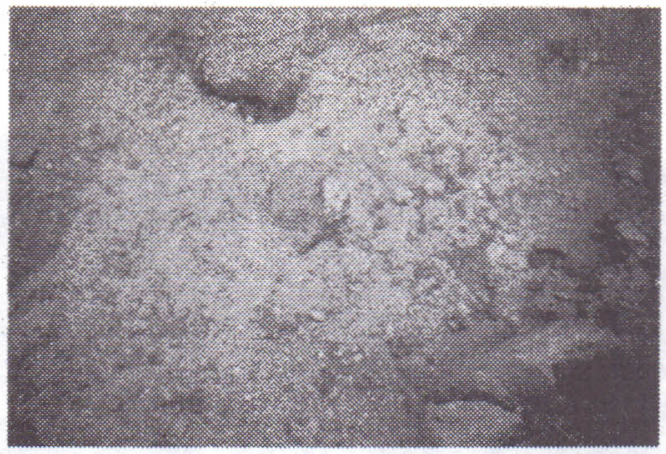

FIGURA 9 : Clastos intraformacionais da Formação Sanga do Cabral.

Os corpos arenosos podem representar sedimentação de origem eólica sob a forma de dunas e interdunas (Faccini,1989). 
A figura 11, Município de Campo Bom, trevo da Avenida dos Estados

(Latitude $29^{\circ} 40^{\prime} 49^{\prime \prime} \mathrm{S}$ e Longitude $51^{\circ} 02^{\prime} 50^{\prime \prime} \mathrm{W}$ ) mostra a ocorrência de associação de vários fácies de uma seqüência fluvial caracterizada como Formação Sanga do Cabral.

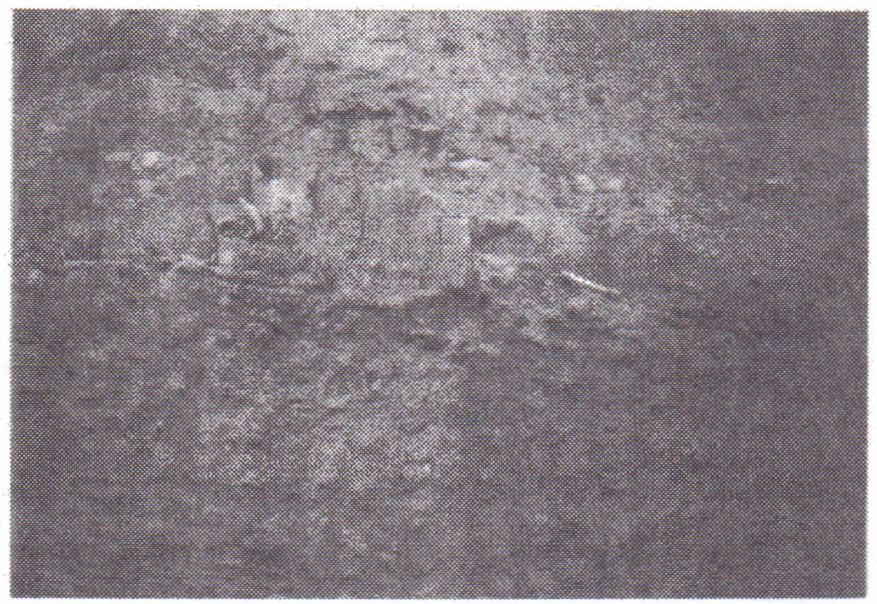

FIGURA 10 : Camadas arenosas silicificadas da Formação Sanga do Cabral.

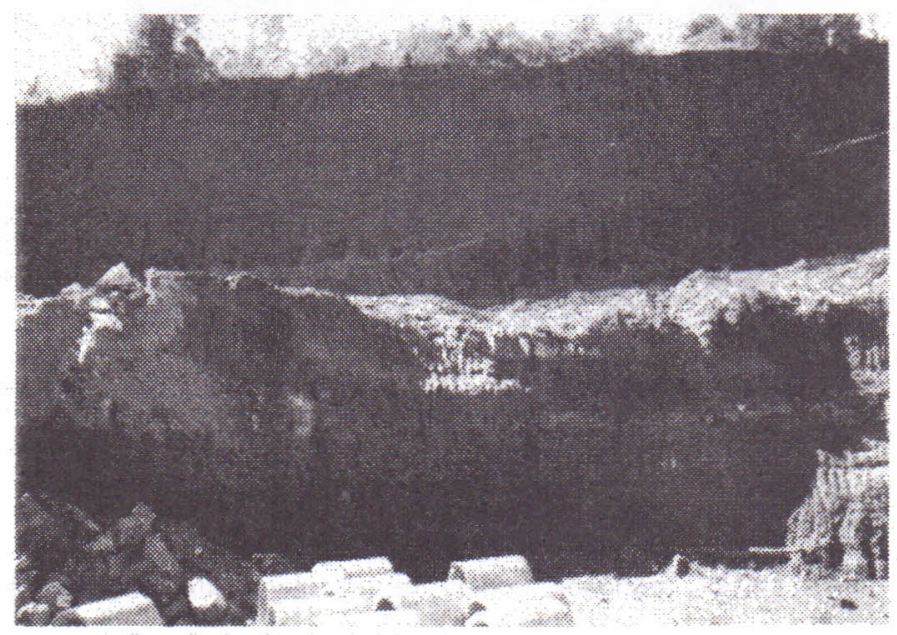

FIGURA 11 : Associação de fácies da seqüência fluvial da Formação Sanga do Cabral, município de Campo Bom. 
Segundo Gamermann (1973), a passagem da Formạção Rosário o Sul para as condições áridas do arenito Botucatu deu-se de uma forma lenta e progressiva, sendo, portanto, transicional. Segundo Faccini (1989), os contatos dessas seqüências são discordantes; contudo, são tanto mais nítidos, quanto mais contrastantes as características de unidade de contato. Ou seja, quando os depósitos da Formação Botucatu estão sobrepostos à unidades fluviais, a identificação é facilitada; por outro lado, quando os arenitos eólicos da Formação Botucatu sobrepõem-se aos arenitos também eólicos da Formação Sanga do Cabral, a diferenciação é dificultada, porque a cor, as estruturas primárias, a textura e a composição são similares.

$\mathrm{Na}$ Formação Botucatu, predominam arenitos eólicos que correspondem a um grande evento climático registrado no Mesozóico. Apresentam, geralmente, cor amarelo-avemelhada, ganulometria variável entre areia fina e média (Tabela 1, em anexo) com grãos de quartzo bem classificados, são levemente feldspáticos e possuem caolinita como argilo-mineral predominante. $\mathrm{O}$ arenito Botucatu apresenta-se bastante resistente quando silicificado mas, quando cimentado por óxido de ferro, mostra-se friável.

Em termos paleambientais, a Formação Botucatu representa depósitos de um extenso deserto de clima árido, onde os depósitos eólicos predominam em muito aos fluviais e lacustres.

A Formação Botucatu está muito bem representada ao norte da área, no município de Novo Hamburgo. Na porção sul, são desenvolvidos processos extrativos dessas litologias. No município de Novo Hamburgo ( ponto com Latitude $29^{\circ} 41^{\prime} 35^{\prime \prime} \mathrm{S}$ e Longitude $51^{\circ} 09^{\prime} 29^{\prime \prime} \mathrm{W}$ ), em uma colina na margem da rodovia BR116 (Fig.12), está representada por arenito de médio a fino com sets longos de estratos cruzados de alto ângulo e pela ocorrência de grain flow. 


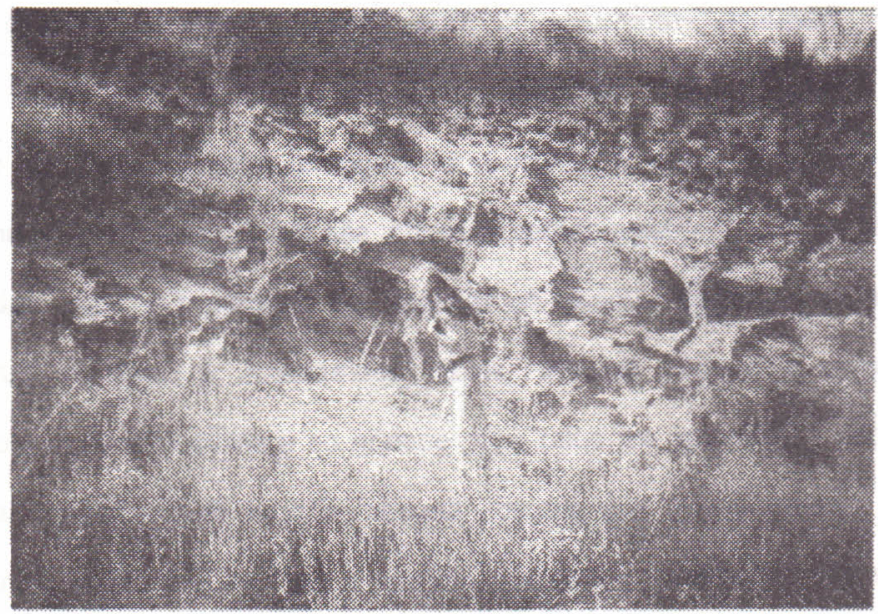

FIGURA 12 : Arenito Botucatu, município de Novo Hamburgo.

Faccini (1989) aponta alguns fatores distintivos entre as formações Botucatu e Sanga do Cabral: (1) os arenitos da Formação Sanga do Cabral são finos a muito finos, são friáveis e contêm matriz argilosa, originada pela decomposição dos feldspatos; (2) os arenitos da Formação Botucatu são isentos de matriz e mais litificados; (3) os arenitos da Formação Sanga do Cabral apresentam clara interdigitação com sedimentos de origem lacustre e fluvial, enquanto os da Formação Botucatu são N-NE, as dunas eólicas da Formação Sanga do Cabral apresentam migrações mais variáveis, sendo comuns as direções S-SW.

Os estudos texturais realizados nas litologias da região de estudo identificam a ampla predominância da fração areia nos litótipos pertencentes à Formação Botucatu, enquanto os arenitos da Formação Sanga do Cabral, têm importante contribuição da fração silte-argila, como pode ser observado na Tabela 1, em anexo. 
Outra característica observada na região é a diferenciação geomorfológica. O arenito Botucatu, quando silicificado, mantém topografia acidentada com cotas elevadas e constitui verdadeiras feições de cuestas dissecadas com presença freqüente de morros testemunhos de faces íngremes. Quando friáveis, permitem o modelamento de morros e de colinas de pequena amplitude. A seqüência litológica da Formação Sanga do Cabral apresenta-se geomorfologicamente como modelados de colinas mais suaves com vertentes convexas.

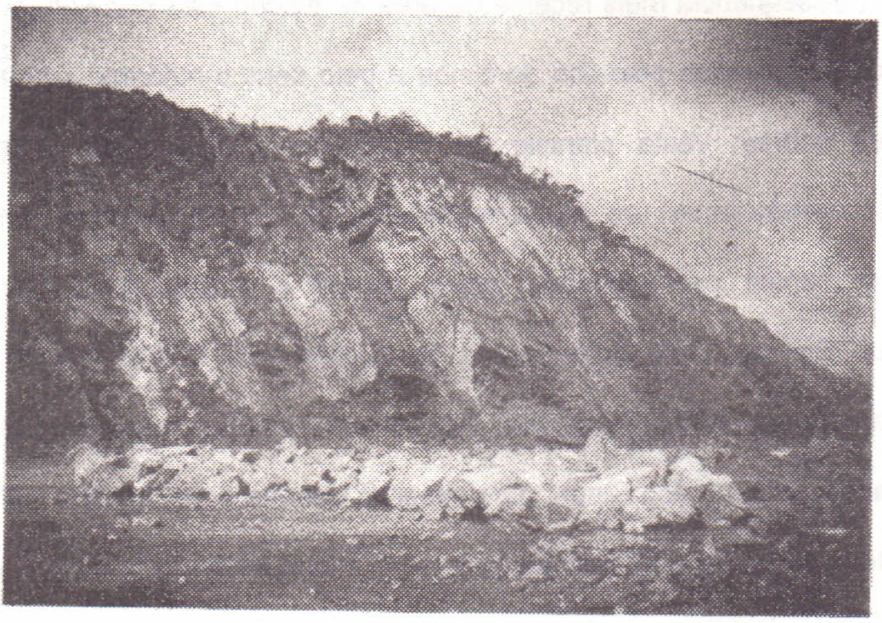

FIGURA 13 : Corpo gabróide da Formação Serra Geral.

Os derrames vulcânicos da Formação Serra Geral encerram os eventos que constituíram a Bacia do Paraná na área de estudo. A presença da Formação Serra Geral é comum ao Norte da quadrícula de Novo Hamburgo. 
ocorrendo como derrames de rochas vulcânicas básicas. O contato Botucatu-Serra Geral na quadrícula de Novo Hamburgo está ao redor da cota altimétrica de 100 metros e esse contato mantém-se aproximadamente uniforme na região.

A Formação Serra Geral, no extremo sul da área de estudo, está representada pelo complexo básico de Lomba Grande (Fig.13). O complexo é composto por corpos hipabissais, onde predomina o corpo de olivina-gabro que corresponde a $95 \%$ do todo. Ele possui granulometria média a grossa e nítida margem resfriada, com notável redução de tamanho dos grãos. A leste do corpo maior, ocorrem dois litótipos de diabásio, distintos pela presença e pela ausência de fenocristais de olivina (Viero \& Roisenberg,1992).

A seqüência mais recente da área de estudo está representada pelos sedimentos depositados pelo Rio do Sinos e pelo seus tributários. Os depósitos aluvionares cobrem vasta planície de inundação e apresentam dois níveis diferentes, evidenciando um rejuvenescimento. O caráter argiloso predomina nesses sedimentos inconsolidados, sendo comum a ocorrência de olarias nas várzeas do Rio dos Sinos. Sondagens realizadas pela CPRM indicam que a espessura geralmente não ultrapassa cinco metros. Enormes massas de areia são transportadas pelo Rio dos Sinos, parcialmente lavadas pelas cheias e utilizadas como matéria prima para construção civil nos municípios da região.

\section{REFERÊNCIAS BIBLIOGRÁFICAS}

ANDREIS, R.R.; BOSSI, G.E.; MONTARDO, D.K. (1992). Geologia da Folha de Rio Pardo - RS, escala 1:100.000. Instituto de Geociências, UFRGS,Mapa n.11 
ANDREIS, R.R.; LAVINA, E.L. \& PAIM, P.S.G. (1984). Geologia da Folha de Novo Hamburgo-RS. IN: BARBERENA, M.C. (Coord.) Geologia dos Recursos Minerais do Sul do Brasil, sub-projeto V: Mapeamento Geológico, Estratigrafia, Recursos Minerais e Paleontologia do Permiano Superior e Triássico do Rio Grande do Sul. Convênio UFRGS-FINEP. Relatório Final, Mapas 9 e 10, inédito.

De RAJA GABAGLIA, G.P. MILANI, E.J. (Coords.) 1990. Origem e Evolução de Bacias Sedimentares. PETROBRÁS. p 135-167.

FACCINI, U.F. 1989 - O Permo-Triassico do Rio Grande do Sul. Curso de PósGraduação em Geociência, UFRGS, 1989 - Dissertação de Mestrado, $121 \mathrm{p}$.

GAMERMANN,N.(1973) - Formação Rosário do Sul, Pesquisa, Porto Alegre, 2(1), p 5-35.

VIERO \& ROISEMBERG, 1992. Petrologia e geoquímica do Complexo Básico de Lomba Grande, RS. Instituto de Geociências, UFRGS, Pesquisa, 19(1) : 41-54.

ZELTER, F., PAULA,C.C., NOWATZKI, C.H. 1992. Mapa Geológico da Folha de São Leopoldo, escala 1:50.000. Acta Geológica Leopoldensia, Mapa n.1. 
TABELA 1 : Análise granulométrica (em porcentagem) das rochas sedimentares da Bacia do Paraná na regiăo de estudo.

\begin{tabular}{|c|c|c|c|c|c|c|c|c|c|c|}
\hline \multirow{3}{*}{$\begin{array}{c}\text { Classificaçáo } \\
\text { granulométrica } \\
\text { de } \\
\text { (Wentworth) }\end{array}$} & \multicolumn{3}{|c|}{ Formação Rio do Rasto } & \multirow{2}{*}{\multicolumn{2}{|c|}{$\begin{array}{c}\begin{array}{c}\text { Formaçăo } \\
\text { Botucatú }\end{array} \\
\text { Fácies } \\
\text { arenosas }\end{array}$}} & \multicolumn{5}{|c|}{ Formação Sanga do Cabral } \\
\hline & \multirow{2}{*}{\begin{tabular}{l|}
$\begin{array}{c}\text { Fácies } \\
\text { finas }\end{array}$ \\
C. Bom \\
\end{tabular}} & \multirow{2}{*}{\begin{tabular}{|c|}
$\begin{array}{c}\mathrm{F} . \\
\text { areno- } \\
\text { basal }\end{array}$ \\
C. Bom \\
\end{tabular}} & \multirow{2}{*}{\begin{tabular}{|l|}
$\begin{array}{l}\text { F.areno } \\
\text { superior }\end{array}$ \\
C. Bom \\
\end{tabular}} & & & \multirow{2}{*}{\begin{tabular}{|l|}
$\begin{array}{c}\text { Arenito } \\
\text { conglom. }\end{array}$ \\
C. Bom \\
\end{tabular}} & \multicolumn{3}{|c|}{ Fácie arenosa } & \multirow{2}{*}{\begin{tabular}{|l|} 
Intraclastos \\
C. Bom \\
\end{tabular}} \\
\hline & & & & N.H. & N.H. & & C. Bom & N.H. & S.L. & \\
\hline Areia grossa & 1,35 & 30,91 & 1,515 & 10,80 & 1,65 & 48,04 & 2,57 & 12,95 & 0,93 & 12,31 \\
\hline Areia média & 6,63 & 35,95 & 6,28 & 24,35 & 43,21 & 19,57 & 10,12 & 5,95 & 7,90 & 3,73 \\
\hline $\begin{array}{l}\text { Areia fina a } \\
\text { muito fina }\end{array}$ & 21,38 & 9,93 & 44,23 & 39,66 & 30,53 & 9,90 & 35,16 & 51,20 & 49,59 & 6,73 \\
\hline Silte & 38,18 & 15,09 & 22,80 & 14,78 & 14,19 & 15,40 & 26,40 & 28,51 & 22,74 & 41,15 \\
\hline Argila & 30,51 & 8,13 & 25,11 & 10,37 & 10,42 & 7,08 & 15,74 & 14,33 & 18,84 & 36,07 \\
\hline
\end{tabular}

